\title{
Renal Replacement Therapy and Concurrent Fluconazole Therapy Increase Linezolid-Related Thrombocytopenia Among Adult Patients
}

\author{
Yueh-Chun Hsu \\ E-Da Hospital \\ Szu-Ying Chen \\ E-Da Hospital \\ Yung-Jun Hung \\ E-Da Hospital \\ Yu-Wei Huang ( $\nabla$ yw.huang0211@gmail.com ) \\ E-Da Hospital
}

\section{Research Article}

Keywords: Linezolid, Thrombocytopenia, Renal replacement therapy, Fluconazole

Posted Date: July 7th, 2021

DOI: https://doi.org/10.21203/rs.3.rs-532929/v2

License: (c) (i) This work is licensed under a Creative Commons Attribution 4.0 International License. Read Full License 


\section{Abstract}

Linezolid has been reported to be associated with thrombocytopenia. However, limited information is available on susceptibility to thrombocytopenia after linezolid usage. We aimed to investigate the risk factors for linezolidassociated thrombocytopenia (LAT). We conducted a retrospective cohort study of patients aged $\geq 18$ years who received linezolid for $\geq 5$ d during hospitalization in 2019. Information was extracted from electronic medical records. Thrombocytopenia was defined as a platelet count of $<100 \times 10^{9} / \mathrm{L}$ or a reduction from baseline $\geq 25 \%$. Binary logistic regression and survival analyses were used to evaluate the risk factors for LAT. A total of 98 patients were enrolled. Thrombocytopenia occurred in $53.1 \%$ patients, with a median of $9 \mathrm{~d}$ after initiation of linezolid. There was no significant difference in the mortality or proportion of platelet transfusions between patients with and without thrombocytopenia. A higher risk of LAT was found in patients who received renal replacement therapy (RRT) (OR 4.8 [1.4-16.4]), concurrent fluconazole (OR 3.5 [1.2-9.8]), or a longer duration of linezolid treatment (OR 1.1 [1.0-1.1]). Patients who received RRT ( 8 vs. $15 \mathrm{~d}$ ) or concurrent fluconazole (11 vs. $15 \mathrm{~d}$ ) had a shorter median time to develop thrombocytopenia. Those who simultaneously received RRT and fluconazole had the shortest median of time (6.5 d) and the highest risk of developing thrombocytopenia (87.5\%).

\section{Introduction}

Linezolid, a synthetic oxazolidinone antibiotic, has a fair activity against gram-positive pathogens. Because of its good tissue penetration, linezolid is a key therapeutic choice for nosocomial lung infections and skin or skin structure infections ${ }^{1}$. An oral bioavailability of $100 \%$ makes it easy to adjust for administration. According to the manufacturer's recommendation ${ }^{2}$, there is no need to adjust the dose for patients with renal impairment or mild-tomoderate hepatic impairment.

Regarding the safety of linezolid, a variety of adverse effects, such as myelosuppression, peripheral and optic neuropathy, serotonin syndrome, and lactic acidosis have been reported ${ }^{2}$. In comparator-controlled phase III studies ${ }^{3}$, diarrhea, nausea, and headaches were frequent adverse effects. Although under longer treatment durations, linezolidtreated patients had a higher potential for lower platelet counts compared to the comparator, the difference was not statistically significant. However, emerging observational studies have demonstrated the thrombocytopenic effect of linezolid ${ }^{4-13}$. Depending on different definitions of thrombocytopenia, the incidence of thrombocytopenia ranged from $16.7-48.4 \%$ in adults treated with intravenous or oral linezolid ${ }^{4-13}$.

Although several studies have highlighted the susceptible population of linezolid-associated thrombocytopenia, the results are inconclusive. Possible risk factors including high daily dose per $\mathrm{kg} 4,6$, long duration $5,8,11,13$, renal impairment ${ }^{5-8,10-13}$, and low baseline platelet counts $9,11,12$ have been reported. One study ${ }^{9}$ showed that carbapenem combination therapy and low baseline platelet count were significant predictors, and the duration of linezolid administration or renal function had little effect. However, a study conducted by Choi et al. ${ }^{11}$ revealed that low-dose aspirin was a possible risk factor, and the effect of carbapenem combination therapy was not significant.

More than $60 \%$ of patients admitted to the intensive care unit may suffer thrombocytopenia ${ }^{14-16}$. Multiple factors predispose an individual to platelet deficiency, including sepsis, major trauma, and drug exposure ${ }^{14-16}$. Medications that may induce thrombocytopenia are as follows: abciximab ${ }^{15}$, amiodarone ${ }^{11}$, aspirin ${ }^{11,15}$, clopidogrel ${ }^{15}$, digoxin ${ }^{11}$, dipyridamole ${ }^{15}$, eptifibatide ${ }^{15}$, fluconazole ${ }^{17}$, haloperidol ${ }^{11}$, heparin ${ }^{11,14-16}$, oxaliplatin ${ }^{16}$, piperacillin ${ }^{11,16}$, rifampin ${ }^{11,16}$, ticlopidine ${ }^{15}$, trimethoprim-sulfamethoxazole ${ }^{11,15,16}$, valproic acid ${ }^{11,15}$, and vancomycin ${ }^{15,16}$. 
In addition to linezolid, a variety of predisposing factors and drugs may contribute to thrombocytopenia. For clinicians, it is urgent to define a susceptible population to avoid harmful outcomes. Therefore, we conducted an observational study to evaluate the risk factors of linezolid-associated thrombocytopenia. However, whether a patient's predisposing factors or combination treatment with certain drugs aggregates linezolid-related thrombocytopenia is still inconclusive.

\section{Methods}

\section{Study design and population}

We designed a retrospective cohort study to investigate the possible risk factors for linezolid-associated thrombocytopenia. Patients $\geq 18$ years and hospitalized at the E-Da hospital from January 1, 2019 to December 31, 2019, were recruited into this study. We reviewed the electronic medical records of patients who received linezolid orally or intravenously for $\geq 5 \mathrm{~d}$. All linezolid prescriptions were approved by the infection specialist. Patients with any of the following were excluded: A linezolid treatment duration $<5 \mathrm{~d}$, baseline platelet count $<100 \times 10^{9} / \mathrm{L}$, received platelet transfusions within $10 \mathrm{~d}$ before the linezolid treatment, platelet count not monitored after starting therapy, had undergone chemotherapy or radiation for malignancy, presence of hematological diseases. Our study adhered to ethical restrictions and was approved by the Institutional Review Board of E-Da Hospital (EMRP-109-142). This observational study was performed by reviewing the medical records and the required informed consent was waived due to the retrospective study nature. The study was conducted accordance the Strengthening the Reporting of Observational Studies in Epidemiology (STROBE) guidelines ${ }^{18}$.

\section{Individual characteristics}

Individual characteristics and information from hospitalization, including age, sex, body weight, height, comorbidity, history of renal replacement therapy (RRT), date of admission, and date of discharge were collected from the medical information system. Diseases that had been documented in medical records more than three times in six months prior to the initiation until the end of therapy were defined as comorbidities. In addition, admission to the intensive care unit during hospitalization, and history of receiving chemotherapy or radiotherapy in the six months prior to initiation until discontinuation of linezolid were also collected.

Information about linezolid usage such as type of infection, route of administration, dosage, and dosing interval were collected from electronic medical records. Previously prescribed glycopeptides, concurrent antibiotics, and combination medications that might affect platelet count and the date of platelet transfusions were reviewed. Combination medications were defined as medications that were co-administrated with linezolid for $\geq 3 \mathrm{~d}$.

\section{Laboratory data}

Laboratory data, such as microbiological isolates, platelet count, and serum creatinine, were collected from electronic medical records.

The baseline platelet count was defined as the latest platelet count prior to linezolid treatment. The percentage change in platelet count was calculated by baseline and the lowest platelet count after initiating therapy. According to the latest version of the Common Terminology Criteria for Adverse Events (CTCAE), version $5{ }^{19}$, thrombocytopenia was defined as a platelet count $<100 \times 10^{9} / \mathrm{L}^{15}$ or a reduction from baseline $\geq 25 \%$. Platelet counts that recovered to $\geq 150 \times 10^{9} / \mathrm{L}$ or baseline, and platelet counts after linezolid discontinuation $\geq 14 \mathrm{~d}$ were also collected. 
The latest data on serum creatinine levels before initiation of linezolid were collected. Baseline renal function was estimated using the Cockcroft-Gault Eq. $2^{0}$. Enrolled patients were classified into four groups: creatinine clearance $(\mathrm{CrCL})<30,30 \leq \mathrm{CrCL}<60, \mathrm{CrCL} \geq 60 \mathrm{~mL} / \mathrm{min}$, and $\mathrm{RRT}$.

\section{Statistical analysis}

Continuous and categorical variables were analyzed using the t-test and chi-square test, respectively. For nonparametric variables, the Mann-Whitney U test or Fisher's exact test was ued instead. The association between risk factors and thrombocytopenia was evaluated using binary logistic regression and adjustment for potential confounders. Variables with a $P$-value $<0.1$, in the univariable model were further evaluated in the multivariable model. Analyses were presented as estimates and $95 \%$ confidence intervals, and $P$-values $<0.05$, were considered significant. The time between initiating the treatment and the occurrence of thrombocytopenia was analyzed using Kaplan-Meier curves and was tested using the log-rank test. Statistical analyses were performed using SAS version 9.4.

\section{Results}

A total of 216 patients were prescribed intravenous or oral linezolid in 2019. After excluding 118 patients with, 98 patients were finally included in this study (Fig. 1). Table 1 shows the individual characteristics of the 98 study subjects stratified by thrombocytopenia. The mean age of all study subjects was $69.0 \pm 15.7$ years and was equal in both sexes. Sixty-five patients (66.3\%) received intravenous linezolid. The average treatment duration of linezolid was $13.9 \pm 7.2 \mathrm{~d}$. Urinary tract infection was observed in $48.0 \%$ of patients, and $52.0 \%$ of patients had a history of intensive care unit admission. Vancomycin-resistant Enterococcus isolates and oxacillin-resistant Staphylococcus isolates were present in $71.7 \%$ and $13.0 \%$ of patients, respectively.

Thrombocytopenia occurred in 52 patients (53.1\%), with a median of $9 \mathrm{~d}$ after initiation of linezolid, and 8 of them (15.4\%) received platelet transfusions. After discontinuation, the median duration of platelet counts returned to normal range was $10 \mathrm{~d}$.

There was no significant difference in mortality $(26.9 \%$ and $23.9 \%, P=0.7330)$ and proportion of platelet transfusions (15.4\% and 4.4\%, $P=0.0716$ ) between those with and without thrombocytopenia. Patients who developed thrombocytopenia had a significantly higher proportion of patients receiving RRT ( $36.5 \%$ vs. $10.9 \%$ ), intravenous administration of linezolid (75.0\% vs. $56.5 \%)$, male (59.6\% vs. $39.1 \%)$, and longer median duration (14.0 vs. $10.5 \mathrm{~d})$. In addition, a higher ratio of diabetes mellitus, chronic kidney disease, and concurrent use of fluconazole were found in thrombocytopenia (Table 1).

Table 2 shows the odds ratios of the risk factors associated with linezolid-associated thrombocytopenia. In the crude model, patients who were male, diabetic, receiving RRT, intravenous linezolid, or concurrent fluconazole therapy were found to have increased odds ratios of linezolid-associated thrombocytopenia compared with their counterparts. In the main model, we found increased odds ratios of linezolid-associated thrombocytopenia in patients who received longer duration of linezolid, RRT, and concurrent fluconazole therapy, with an OR of 1.071 (95\% $\mathrm{Cl} 1.000-1.146), 0 R$ 4.773 (95\% Cl 1.390-16.389), and OR 3.474 (95\% Cl 1.230-9.810), respectively.

Figure 2 illustrates the Kaplan-Meier survival curves of linezolid-associated thrombocytopenia events in patients who received RRT or fluconazole treatment. We found that patients who underwent RRT had a shorter median time (with vs. without RRT: 8 vs. 15 d, log-rank test $P=0.0043$; Fig. 2 ) and higher risk (with vs. without RRT: $79.2 \%$ vs. $44.6 \%, P=$ 0.0032) of developing linezolid-associated thrombocytopenia. However, there was no significant difference in the 
incidence of thrombocytopenia between $\mathrm{CrCL}<30 \otimes 30 \leq \mathrm{CrCL}<60$ and $\mathrm{CrCL} \geq 60 \mathrm{~mL} / \mathrm{min}$ (results detailed in Supplementary Fig. S1). Among the 24 patients who received RRT, 16 (67\%) had end-stage renal disease (ESRD) who underwent RRT, while the others underwent emergent RRT for acute kidney injury (AKI). A slightly higher percentage of thrombocytopenia was noted among ESRD patients than among AKI patients, but the difference was not statistically significant (ESRD vs. AKI: $81.25 \%$ vs. $75.00 \%, P=0.7223$ ).

Patients who received fluconazole were also observed to have a shorter median time (with vs. without fluconazole: 11 vs. 15 d, log-rank test $P=0.0332$; Fig. 2 ) and higher risk (with vs. without fluconazole: $66.7 \%$ vs. $45.2 \%, P=0.0397$ ) of developing linezolid-associated thrombocytopenia.

Figure 3 illustrates the subgroup analyses of linezolid-associated thrombocytopenia stratified by RRT and fluconazole therapy. The incidence of linezolid-associated thrombocytopenia was 34.8\%, $60.7 \%$, $70.5 \%$, and $84.5 \%$, respectively, showing an incremental trend in subgroups without RRT and fluconazole, with fluconazole, with RRT, and with both RRT and fluconazole. Multiple logistic regression showed that the odds ratios were 13.125 (95\% $\mathrm{Cl} 1.482-1116.267)$, 5.625 (95\% Cl 1.558-20.312), and 2.898 (95\% Cl 1.097-7.654), respectively, among patients who received concurrent RRT and fluconazole, RRT alone, and fluconazole alone compared with patients who did not receive RRT and fluconazole therapy. 
Table 1

Individual and characteristics data of enrolled patients. BMI, body mass index; $\mathrm{CrCL}$, creatinine clearance;

\begin{tabular}{|c|c|c|c|}
\hline Characteristics & $\begin{array}{l}\text { With thrombocytopenia }(n= \\
52)\end{array}$ & $\begin{array}{l}\text { Without thrombocytopenia }(n= \\
46)\end{array}$ & $\begin{array}{l}P \\
\text { value }\end{array}$ \\
\hline Age (year), mean \pm SD & $71.0 \pm 16.1$ & $66.7 \pm 15.2$ & 0.1824 \\
\hline Male & $31(59.62)$ & $18(39.13)$ & 0.0430 \\
\hline $\mathrm{BMI}\left(\mathrm{kg} / \mathrm{m}^{2}\right)$, mean $\pm \mathrm{SD}$ & $24.9 \pm 4.4$ & $25.0 \pm 6.3$ & 0.9529 \\
\hline \multicolumn{4}{|l|}{ Renal function, $\mathrm{mL} / \mathrm{min}$} \\
\hline $\mathrm{CrCL} \geq 60$ & $12(23.08)$ & $18(39.13)$ & \multirow[t]{4}{*}{0.0277} \\
\hline $30 \leq \mathrm{CrCL}<60$ & $11(21.15)$ & $12(26.09)$ & \\
\hline $\mathrm{CrCL}<30$ & $10(19.23)$ & $11(23.91)$ & \\
\hline Renal replacement therapy & $19(36.54)$ & $5(10.87)$ & \\
\hline $\begin{array}{l}\text { Intensive care unit admission, no } \\
(\%)\end{array}$ & $30(57.69)$ & $21(45.65)$ & 0.2338 \\
\hline \multicolumn{4}{|l|}{ Comorbidity, no (\%) } \\
\hline Hypertension & $36(69.23)$ & $30(65.22)$ & 0.6724 \\
\hline Diabetes mellitus & $29(55.77)$ & $14(30.43)$ & 0.0117 \\
\hline Chronic kidney disease & $20(38.46)$ & $7(15.22)$ & 0.0102 \\
\hline Liver diseases & $9(17.31)$ & $6(13.04)$ & 0.5585 \\
\hline \multicolumn{4}{|l|}{ Platelet $\left(10^{9} / \mathrm{L}\right)$, mean $\pm \mathrm{SD}$} \\
\hline Baseline & $283.8 \pm 136.1$ & $270.7 \pm 101.3$ & 0.5870 \\
\hline Nadir during therapy & $131.3 \pm 82.9$ & $290.7 \pm 111.7$ & $<.0001$ \\
\hline After discontinuation ( $\geq 14 \mathrm{~d}$ ) & $280.5 \pm 148.9$ & $300.0 \pm 122.6$ & 0.5491 \\
\hline \multicolumn{4}{|l|}{ Previous glycopeptide, no (\%) } \\
\hline None & $24(46.15)$ & $24(52.17)$ & \multirow[t]{4}{*}{0.4908} \\
\hline Vancomycin & $5(9.62)$ & $7(15.22)$ & \\
\hline Teicoplanin & $22(42.31)$ & $13(28.26)$ & \\
\hline Both vancomycin and teicoplanin & $1(1.92)$ & $2(4.35)$ & \\
\hline Median duration of linezolid (day) & 14.0 & 10.5 & 0.0310 \\
\hline \multicolumn{4}{|l|}{ Route of linezolid, no (\%) } \\
\hline Oral & $7(13.46)$ & $16(34.78)$ & 0.0456 \\
\hline Intravenous & $39(75.00)$ & $26(56.52)$ & \\
\hline IV and oral & $6(11.54)$ & $4(8.70)$ & \\
\hline
\end{tabular}




\begin{tabular}{|c|c|c|c|}
\hline Characteristics & $\begin{array}{l}\text { With thrombocytopenia }(n= \\
52)\end{array}$ & $\begin{array}{l}\text { Without thrombocytopenia ( } n= \\
\text { 46) }\end{array}$ & $\begin{array}{l}P \\
\text { value }\end{array}$ \\
\hline Urinary tract infection & $25(48.08)$ & $22(47.83)$ & \multirow[t]{6}{*}{0.4087} \\
\hline Skin and soft tissue infection & $9(17.31)$ & $5(10.87)$ & \\
\hline Bacteremia & $8(15.38)$ & $7(15.22)$ & \\
\hline Intra-abdominal infection & $6(11.54)$ & $4(8.70)$ & \\
\hline Respiratory infection & $1(1.92)$ & $6(13.04)$ & \\
\hline Others & $3(5.77)$ & $2(4.35)$ & \\
\hline \multicolumn{4}{|l|}{ Microbiological isolate, no (\%) } \\
\hline Enterococcus sp. & $6(11.54)$ & $3(6.52)$ & \multirow[t]{4}{*}{0.3857} \\
\hline VRE strain & $37(71.15)$ & $29(60.00)$ & \\
\hline $\begin{array}{l}\text { Oxacillin-resistant } \\
\text { Staphylococcus }\end{array}$ & $4(7.69)$ & $8(17.39)$ & \\
\hline Others & $5(9.62)$ & $6(13.04)$ & \\
\hline \multicolumn{4}{|l|}{ Concurrent medications, no (\%) } \\
\hline Aspirin or clopidogrel & $9(17.31)$ & $7(15.22)$ & 0.7799 \\
\hline Amiodarone & $2(3.85)$ & $5(10.87)$ & 0.2478 \\
\hline Piperacillin/tazobactam & $5(9.62)$ & $4(8.70)$ & 0.2695 \\
\hline Cephalosporin & $15(28.85)$ & $10(21.74)$ & 0.4205 \\
\hline Carbapenem & $27(51.92)$ & $16(34.78)$ & 0.0879 \\
\hline Colistin & $10(19.23)$ & $9(19.57)$ & 0.9667 \\
\hline Fluconazole & $24(46.15)$ & $12(26.09)$ & 0.0397 \\
\hline Fluoroquinolone & $16(30.77)$ & $13(28.26)$ & 0.7860 \\
\hline
\end{tabular}

IV, intravenous; VRE, vancomycin-resistant enterococcus; SD, standard deviation 
Table 2

Association between risk factors and incidence of linezolid-associated thrombocytopenia. Main model was adjusted for gender, treatment duration, routes of administration, renal replacement therapy, diabetes mellitus, concurrent carbapenem, and concurrent fluconazole therapy. BMI, body mass index; ICU, intensive care unit; IV, intravenous; $\mathrm{Cl}$, confidence interval

\begin{tabular}{|c|c|c|c|c|c|c|}
\hline \multirow[b]{2}{*}{ Variables } & \multicolumn{3}{|c|}{ Crude model } & \multicolumn{3}{|c|}{ Main model } \\
\hline & OR & $95 \% \mathrm{Cl}$ & P-value & OR & $95 \% \mathrm{Cl}$ & P-value \\
\hline Age & 1.018 & $0.992-1.045$ & 0.1851 & - & - & - \\
\hline Male & 2.296 & $1.021-5.166$ & 0.0445 & 2.210 & $0.829-5.890$ & 0.1127 \\
\hline BMI & 0.998 & $0.926-1.075$ & 0.9512 & - & - & - \\
\hline Linezolid treatment duration & 1.057 & $0.992-1.125$ & 0.0861 & 1.071 & $1.000-1.146$ & 0.0506 \\
\hline \multicolumn{7}{|l|}{ Routes of linezolid } \\
\hline IV & 3.427 & $1.239-9.480$ & 0.0176 & 2.950 & $0.884-9.847$ & 0.0786 \\
\hline Both IV and oral & 3.427 & $0.731-16.080$ & 0.1183 & 1.314 & $0.187-9.236$ & 0.7840 \\
\hline Baseline platelet count & 1.001 & $0.998-1.004$ & 0.5900 & - & - & - \\
\hline ICU admission & 1.623 & $0.730-3.611$ & 0.2349 & - & - & - \\
\hline Renal replacement therapy & 4.721 & $1.593-13.993$ & 0.0051 & 4.773 & $1.390-16.389$ & 0.0130 \\
\hline Hypertension & 1.200 & $0.515-2.795$ & 0.6726 & - & - & - \\
\hline Diabetes mellitus & 2.882 & $1.253-6.628$ & 0.0128 & 1.698 & $0.635-4.544$ & 0.2917 \\
\hline Liver diseases & 1.395 & $0.456-4.273$ & 0.5596 & - & - & - \\
\hline Cephalosporin & 1.459 & $0.580-3.671$ & 0.4218 & - & - & - \\
\hline Carbapenem & 2.025 & $0.896-4.574$ & 0.0897 & 1.056 & $0.397-2.813$ & 0.9125 \\
\hline Fluconazole & 2.428 & $1.033-5.708$ & 0.0419 & 3.474 & $1.230-9.810$ & 0.0187 \\
\hline Fluoroquinolone & 1.128 & $0.472-2.695$ & 0.7865 & - & - & - \\
\hline
\end{tabular}

\section{Discussion}

To the best of our knowledge, this study is the first to demonstrate that patients who received RRT or concurrent fluconazole treatment may have a higher incidence of linezolid-associated thrombocytopenia. In addition, we revealed the real-world situation and the association between clinical risk factors and linezolid-associated thrombocytopenia.

By performing binary logistic regression, RRT, concurrent fluconazole therapy, and longer duration of linezolid were identified as risk factors for linezolid-associated thrombocytopenia.

We discovered that patients who received RRT had a significantly higher risk (with vs. without RRT: $79.2 \%$ vs. $44.6 \%$, $P=0.0032$ ) and shorter median time (with vs. without RRT: 8 vs. 15 days, $P=0.0043$ ) to have thrombocytopenia. Our finding was compatible with Hanai et al.'s results, which showed an onset time of $8.5 \mathrm{~d}$ in patients undergoing hemodialysis ${ }^{8}$. Hirano et al. found that patients with $\mathrm{CrCL}<30 \mathrm{~mL} / \mathrm{min}(60.0 \%)$ had a significantly higher incidence 
of thrombocytopenia then those with $\mathrm{CrCL}>60 \mathrm{~mL} / \mathrm{min}(26.4 \%){ }^{5}$. Moraza et al. and Hanai et al. ${ }^{8}$ reported similar findings ${ }^{7}$. Several studies have revealed that renal function plays a critical role in thrombocytopenia associated with linezolid ${ }^{5-8,10,12,21}$. The manufacturer recommends that the pharmacokinetic parameters of the parent drug are not transformed ${ }^{2}$, and that no dosage adjustment is needed for renal impairment. However, a higher incidence of thrombocytopenia was noted among our patients who received RRT. Brier et al. concluded that the levels of two primary metabolites (PNU-142586 and PNU-142300) were higher in patients requiring hemodialysis ${ }^{22}$. Matsumoto et al. suggested that renal impairment elevated linezolid trough concentration, and higher drug exposure might be related to thrombocytopenia ${ }^{23}$. Considering the higher possibility of thrombocytopenia in renal dysfunction, physicians should be aware of the harmful outcomes, although the mechanism of linezolid-associated remains unclear.

The literature reports fluconazole-associated thrombocytopenia limited to several case reports. Pasikhova et al. reported a case of fluconazole-associated agranulocytosis with thrombocytopenia ${ }^{17}$. One population-based study enrolled 54,803 users of either fluconazole or itraconazole, and only 1 of 34,220 fluconazole users had thrombocytopenia ${ }^{24}$. So far, no interaction between fluconazole and linezolid has been found ${ }^{25}$. Little information is available regarding the underlying fluconazole and linezolid-associated thrombocytopenia. We suppose that the use of fluconazole may indicate more severe sepsis, and sepsis may be the direct result of thrombocytopenia ${ }^{26}$. Therefore, further studies are necessary.

We found that patients treated with linezolid for $\geq 14 \mathrm{~d}$ had a relatively higher frequency of thrombocytopenia (duration $\geq 14$ d vs. $14>$ duration $\geq 5$ d: $63.83 \%$ vs. $43.14 \%, P=0.0403$ ) (results detailed in Supplementary Fig. S2). Our results are compatible with those of other studies. Hirano et al. ${ }^{5}$ and Takahashi et al. ${ }^{13}$ reported a higher incidence of thrombocytopenia among patients with linezolid duration $\geq 14 \mathrm{~d}$. Choi et al. ${ }^{11}$ even suggested an increased odds ratio for linezolid duration $\geq 7 \mathrm{~d}$. Therefore, we suggest monitoring platelet counts for prolonged durations of linezolid administration, especially for those who received RRT.

According to recent studies, the incidence of thrombocytopenia ranged from $16.7-48.4 \%$ in adults treated with linezolid ${ }^{4-13}$. Kim et al. ${ }^{10}$ revealed a $48.3 \%$ risk of thrombocytopenia in a cohort of 60 ICU patients, and thrombocytopenia was defined as a platelet count of $<150 \times 10^{9} / \mathrm{L}$ or a decrease of at least $50 \%$ from the baseline. The relatively higher incidence (53.1\%) in our study could have resulted from different disease severities and definitions of thrombocytopenia.

Our data showed that patients with diabetes mellitus had twice the risk of thrombocytopenia. However, this was not significant after adjusting for confounding factors. Diabetic kidney disease, a microvascular complication, frequently leads patients to undergo dialysis or renal transplantation ${ }^{27}$. Consequently, a higher proportion of diabetes mellitus in the thrombocytopenic group is anticipated. Regarding the administration route, oral-form linezolid was mostly prescribed for discharge in our study. This could be a possible explanation for the higher ratio of intravenous linezolid in patients with thrombocytopenia. Our results were compatible with the findings of Takahashi et al. ${ }^{13}$, which showed that oral linezolid decreased the risk of thrombocytopenia.

However, the mechanism underlying linezolid-associated thrombocytopenia remains unclear. Several mechanisms have been proposed. For instance, immune-mediated thrombocytopenia has been proposed by Bernstein et al. ${ }^{28}$. Other theories, including the suppression of platelets release from mature megakaryocytes ${ }^{29}$, and Tsuji et al. assumed that the inhibition of the platelet formation was the most common mechanism ${ }^{30}$. Many studies reported that the linezolid-associated adverse reactions were related to linezolid trough concentration $\left(C_{\min }\right)^{31,32}$. Cojutti et al. 
33 monitored patients' $C_{\min }$ for dose adjustment at day 3-5 of therapy, and 2-8 $\mathrm{mg} / \mathrm{L}$ was taken as desired range for $\mathrm{C}_{\text {min }}$. Peripheral venous blood samples were collected $5 \mathrm{~min}$ prior to the subsequent dose. Levels of linezolid were analyzed by a validated HPLC analysis method. However, more studies are necessary to clarify the approach of dose adjustment.

Several clinical factors might also affect platelets, such as a history of surgery and recent transfusions ${ }^{34}$. Using radionuclides, the mean life span of transfused platelets in humans was $9.9 \pm 0.6 d^{35-38}$. Therefore, we excluded patients who received platelet transfusions $\leq 10 \mathrm{~d}$ before initiation of linezolid. Moreover, the material of the dialyzer may cause thrombocytopenia; polysulfone membranes and amounts of polyvinylpyrrolidone are thought to be related to its occurrence, but the exact mechanism remains to be elucidated ${ }^{39}$.

Our observational cohort study has several limitations. First, due to the retrospective nature of the study design, we could not make causal inferences. Second, means of monitoring concentrations of linezolid and its metabolites were not available, and it was difficult to evaluate the pharmacokinetic parameters of linezolid in thrombocytopenic patients. Monitoring linezolid $\mathrm{C}_{\min }$ at steady-state condition may be a feasible approach. However, therapeutic drug monitoring of linezolid is in experimental stage, and more studies are warranted.

\section{Conclusions}

Renal adjustment is not required according to the official recommendation. However, in our study, we found that the duration of treatment, RRT, and concurrent fluconazole were significantly associated with the risk of thrombocytopenia. Patients who received RRT had a significantly shorter median time to thrombocytopenia after initiation of linezolid. Careful monitoring of platelets is warranted for patients with renal impairment, especially for those already receiving RRT. However, due to the retrospective nature of our study, large randomized control trials are warranted to verify the association between possible clinical factors and the risk of linezolid-associated thrombocytopenia.

\section{Abbreviations}

AKI: acute kidney injury; BMI: body mass index; Cl: Confidence interval; CKD: Chronic kidney disease; CrCL: creatinine clearance; CTCAE: Common Terminology Criteria for Adverse Events; ESRD: end stage renal disease; ICU: intensive care unit; IV: intravenous; OR: odds ratio; LAT: linezolid-associated thrombocytopenia, RRT: renal replacement therapy; SD: standard deviation; VRE: vancomycin-resistant enterococcus.

\section{Declarations}

\section{Data availability statement}

The datasets analysed during the current study are available from the corresponding author on reasonable request.

\section{Acknowledgments}

We would like to thank Lei-Yu Chang for offering help to submit ethics approval and Wan-Yi Chang-Chien for providing assistance on performing statistical analysis.

\section{Authors' contributions}

Page $10 / 16$ 
Y.C.H. designed the study, reviewed the medical records, collected data, performed the statistical analysis and wrote the manuscript. Y.W.H. designed the study, provided medical opinions and revised the manuscript. S.Y.C. provided statistical assistance and revised the manuscript. Y.J.H. provided hospital resources and related assistance and helped to seek statistical advice. All authors reviewed the manuscript.

\section{Competing interests}

The authors declare no competing interests

\section{Funding}

This study was not funded by any party.

\section{Ethics approval and consent to participate}

This study adhered to ethical restriction and was approved by institutional review board of E-Da hospital. Approval number was EMRP-109-142.

\section{References}

1. Dryden, M. S. Linezolid pharmacokinetics and pharmacodynamics in clinical treatment. J Antimicrob Chemother 66 Suppl 4, iv7-iv15, https://doi.org/10.1093/jac/dkr072 (2011).

2. Product Information: ZYVOX(R) intravenous injection, oral tablets, oral suspension, linezolid intravenous injection, oral tablets, oral suspension., Preprint at https://www.accessdata.fda.gov/scripts/cder/daf/index.cfm (2020).

3. Rubinstein, E. et al. Worldwide assessment of linezolid's clinical safety and tolerability: comparator-controlled phase III studies. Antimicrob Agents Chemother 47, 1824-1831, https://doi.org/10.1128/aac.47.6.18241831.2003 (2003).

4. Niwa, T. et al. Retrospective cohort chart review study of factors associated with the development of thrombocytopenia in adult Japanese patients who received intravenous linezolid therapy. Clin Ther 31, 21262133, https://doi.org/10.1016/j.clinthera.2009.10.017 (2009).

5. Hirano, R., Sakamoto, Y., Tachibana, N. \& Ohnishi, M. Retrospective analysis of the risk factors for linezolidinduced thrombocytopenia in adult Japanese patients. Int J Clin Pharm 36, 795-799, https://doi.org/10.1007/s11096-014-9961-6 (2014).

6. Natsumoto, B., Yokota, K., Omata, F. \& Furukawa, K. Risk factors for linezolid-associated thrombocytopenia in adult patients. Infection 42, 1007-1012, https://doi.org/10.1007/s15010-014-0674-5 (2014).

7. Moraza, L., Leache, L., Aquerreta, I. \& Ortega, A. Linezolid-induced haematological toxicity. Farm Hosp 39, 320326, https://doi.org/10.7399/fh.2015.39.6.8305 (2015).

8. Hanai, Y. et al. A retrospective study of the risk factors for linezolid-induced thrombocytopenia and anemia. $J$ Infect Chemother 22, 536-542, https://doi.org/10.1016/j.jiac.2016.05.003 (2016).

9. Kaya Kilic, E. et al. Risk factors for linezolid-associated thrombocytopenia and negative effect of carbapenem combination. J Infect Dev Ctries 13, 886-891, https://doi.org/10.3855/jidc.10859 (2019).

10. Kim, H. S., Lee, E., Cho, Y. J., Lee, Y. J. \& Rhie, S. J. Linezolid-induced thrombocytopenia increases mortality risk in intensive care unit patients, a 10 year retrospective study. J Clin Pharm Ther 44, 84-90, https://doi.org/10.1111/jcpt.12762 (2019).

Page $11 / 16$ 
11. Choi, G. W. et al. Risk factors for linezolid-induced thrombocytopenia in patients without haemato-oncologic diseases. Basic Clin Pharmacol Toxico/ 124, 228-234, https://doi.org/10.1111/bcpt.13123 (2019).

12. Lima, L. S. et al. A retrospective cohort study to screen linezolid-induced thrombocytopenia in adult patients hospitalized in the Midwestern Region of Brazil. Hematol Transfus Cell Ther 42, 230-237, https://doi.org/10.1016/j.htct.2019.07.004 (2020).

13. Takahashi, Y. et al. Risk factors associated with the development of thrombocytopenia in patients who received linezolid therapy. J Infect Chemother 17, 382-387, https://doi.org/10.1007/s10156-010-0182-1 (2011).

14. Zarychanski, R. \& Houston, D. S. Assessing thrombocytopenia in the intensive care unit: the past, present, and future. Hematology Am Soc Hematol Educ Program 2017, 660-666, https://doi.org/10.1182/asheducation2017.1.660 (2017).

15. Ostadi, Z., Shadvar, K., Sanaie, S., Mahmoodpoor, A. \& Saghaleini, S. H. Thrombocytopenia in the intensive care unit. Pak J Med Sci 35, 282-287, https://doi.org/10.12669/pjms.35.1.19 (2019).

16. Aluru, N. \& Samavedam, S. Thrombocytopenia in Intensive Care Unit. Indian J Crit Care Med 23, S185-s188, https://doi.org/10.5005/jp-journals-10071-23249 (2019).

17. Pasikhova, Y. \& Ludlow, S. P. Fluconazole associated agranulocytosis and thrombocytopenia. Int J Clin Pharm 36, 268-270, https://doi.org/10.1007/s11096-014-9914-0 (2014).

18. Vandenbroucke, J. P. et al. Strengthening the Reporting of Observational Studies in Epidemiology (STROBE): explanation and elaboration. Int J Surg 12, 1500-1524, https://doi.org/10.1016/j.ijsu.2014.07.014 (2014).

19. Common Terminology Criteria for Adverse Events (CTCAE) Version 5.0, Preprint at https://ctep.cancer.gov/protocolDevelopment/electronic_applications/docs/CTCAE_v5_Quick_Reference_5x7.pdf (2020).

20. Cockcroft, D. W. \& Gault, M. H. Prediction of creatinine clearance from serum creatinine. Nephron 16, 31-41, https://doi.org/10.1159/000180580 (1976).

21. Kato, H. et al. Bicytopenia, especially thrombocytopenia in hemodialysis and non-hemodialysis patients treated with linezolid therapy. J Infect Chemother 21, 707-712, https://doi.org/10.1016/j.jiac.2015.06.007 (2015).

22. Brier, M. E. et al. Pharmacokinetics of linezolid in subjects with renal dysfunction. Antimicrob Agents Chemother 47, 2775-2780, https://doi.org/10.1128/aac.47.9.2775-2780.2003 (2003).

23. Matsumoto, K. et al. Higher linezolid exposure and higher frequency of thrombocytopenia in patients with renal dysfunction. Int J Antimicrob Agents 36, 179-181, https://doi.org/10.1016/j.ijantimicag.2010.02.019 (2010).

24. Bradbury, B. D. \& Jick, S. S. Itraconazole and fluconazole and certain rare, serious adverse events. Pharmacotherapy 22, 697-700, https://doi.org/10.1592/phco.22.9.697.34072 (2002).

25. Hashemian, S. M. R., Farhadi, T. \& Ganjparvar, M. Linezolid: a review of its properties, function, and use in critical care. Drug Des Devel Ther 12, 1759-1767, https://doi.org/10.2147/dddt.S164515 (2018).

26. Larkin, C. M., Santos-Martinez, M. J., Ryan, T. \& Radomski, M. W. Sepsis-associated thrombocytopenia. Thromb Res 141, 11-16, https://doi.org/10.1016/j.thromres.2016.02.022 (2016).

27. Braunwald, E. Diabetes, heart failure, and renal dysfunction: The vicious circles. Prog Cardiovasc Dis 62, 298-302, https://doi.org/10.1016/j.pcad.2019.07.003 (2019).

28. Bernstein, W. B., Trotta, R. F., Rector, J. T., Tjaden, J. A. \& Barile, A. J. Mechanisms for linezolid-induced anemia and thrombocytopenia. Ann Pharmacother 37, 517-520, https://doi.org/10.1345/aph.1C361 (2003).

29. Tajima, M. et al. Linezolid-Induced Thrombocytopenia Is Caused by Suppression of Platelet Production via Phosphorylation of Myosin Light Chain 2. Biol Pharm Bul/39, 1846-1851, https://doi.org/10.1248/bpb.b1600427 (2016). 
30. Tsuji, Y. et al. Population pharmacokinetics and pharmacodynamics of linezolid-induced thrombocytopenia in hospitalized patients. Br J Clin Pharmaco/ 83, 1758-1772, https://doi.org/10.1111/bcp.13262 (2017).

31. Nukui, Y. et al. High plasma linezolid concentration and impaired renal function affect development of linezolidinduced thrombocytopenia. J Antimicrob Chemother 68, 2128-2133, https://doi.org/10.1093/jac/dkt133 (2013).

32. Kawasuji, H. et al. Proposal of initial and maintenance dosing regimens with linezolid for renal impairment patients. BMC Pharmacol Toxicol 22, 13, https://doi.org/10.1186/s40360-021-00479-w (2021).

33. Cojutti, P. G., Merelli, M., Bassetti, M. \& Pea, F. Proactive therapeutic drug monitoring (TDM) may be helpful in managing long-term treatment with linezolid safely: findings from a monocentric, prospective, open-label, interventional study. J Antimicrob Chemother 74, 3588-3595, https://doi.org/10.1093/jac/dkz374 (2019).

34. Gauer, R. L. \& Braun, M. M. Thrombocytopenia. Am Fam Physician 85, 612-622, (2012).

35. Harker, L. A. \& Finch, C. A. Thrombokinetics in man. J Clin Invest 48, 963-974, https://doi.org/10.1172/jci106077 (1969).

36. Richard J. Davey, J. P. A. Post-Transfusion Red Blood Cell and Platelet Survival and Kinetics: Basic Principles and Practical Aspects. 455-466, (2007).

37. H., A. R. Blood platelet kinetics and platelet transfusion. The Journal of clinical investigation 123, 4564-4565, https://doi.org/https://doi.org/10.1172/JCl70335 (2013).

38. Richard J.Davey, J. P. A. Blood Banking and Transfusion Medicine. Second edn, 455-466 (2007).

39. Daugirdas, J. T. \& Bernardo, A. A. Hemodialysis effect on platelet count and function and hemodialysisassociated thrombocytopenia. Kidney Int 82, 147-157, https://doi.org/10.1038/ki.2012.130 (2012).

\section{Figures}




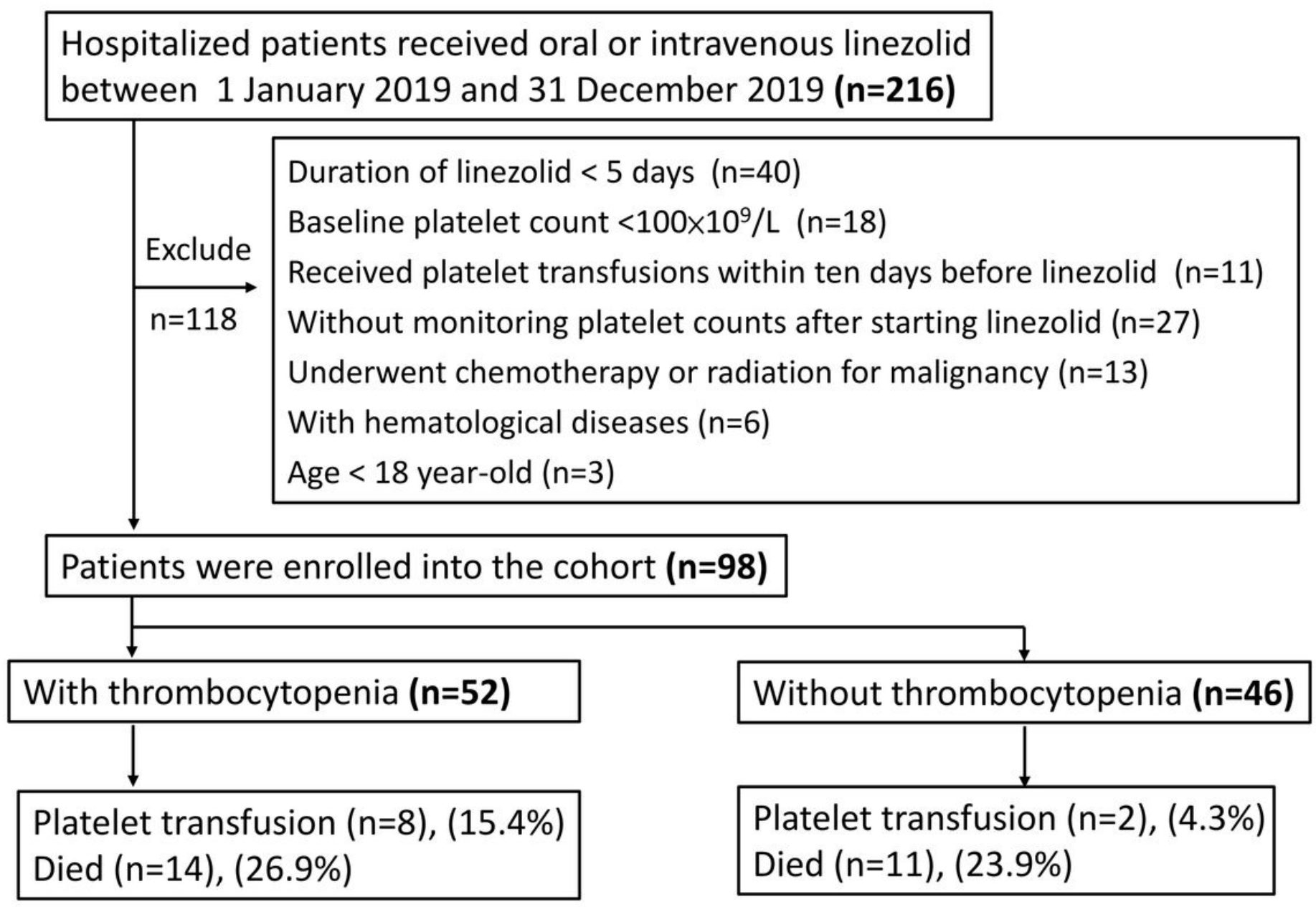

Figure 1

Flow chart showing enrollment into the study and clinical outcomes. 
A

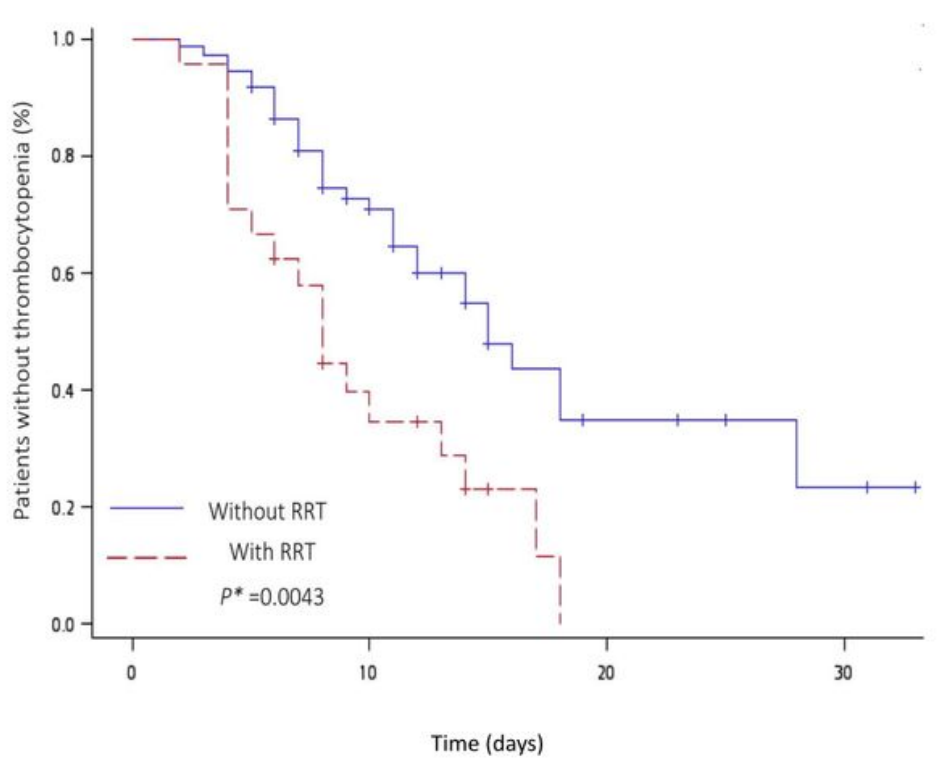

B

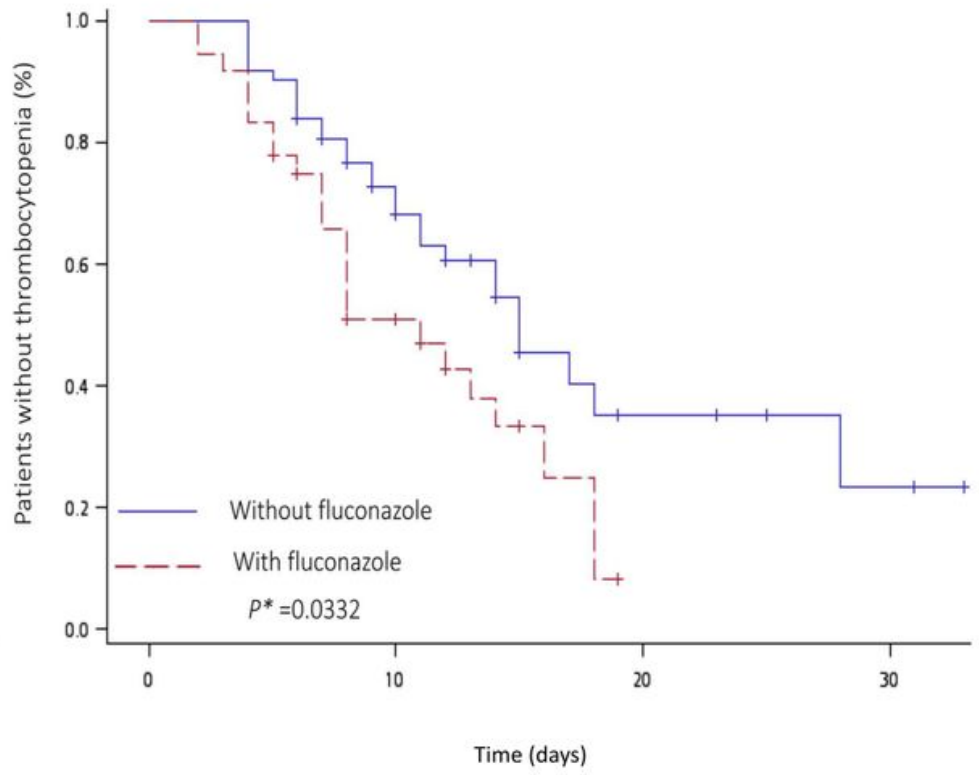

(*significant difference at $p \leq 0.05$ )

\section{Figure 2}

Kaplan-Meier survival curves to reveal the impact on the incidence of thrombocytopenia. (A) Renal replacement therapy (RRT). (B) Fluconazole. Difference between groups were tested by log-rank test. Patients who received RRT (log-rank test $\mathrm{P}=0.043$ ) or fluconazole treatment (log-rank test $\mathrm{P}=0.0332$ ) showed significantly higher risk of developing linezolid-associated thrombocytopenia. 


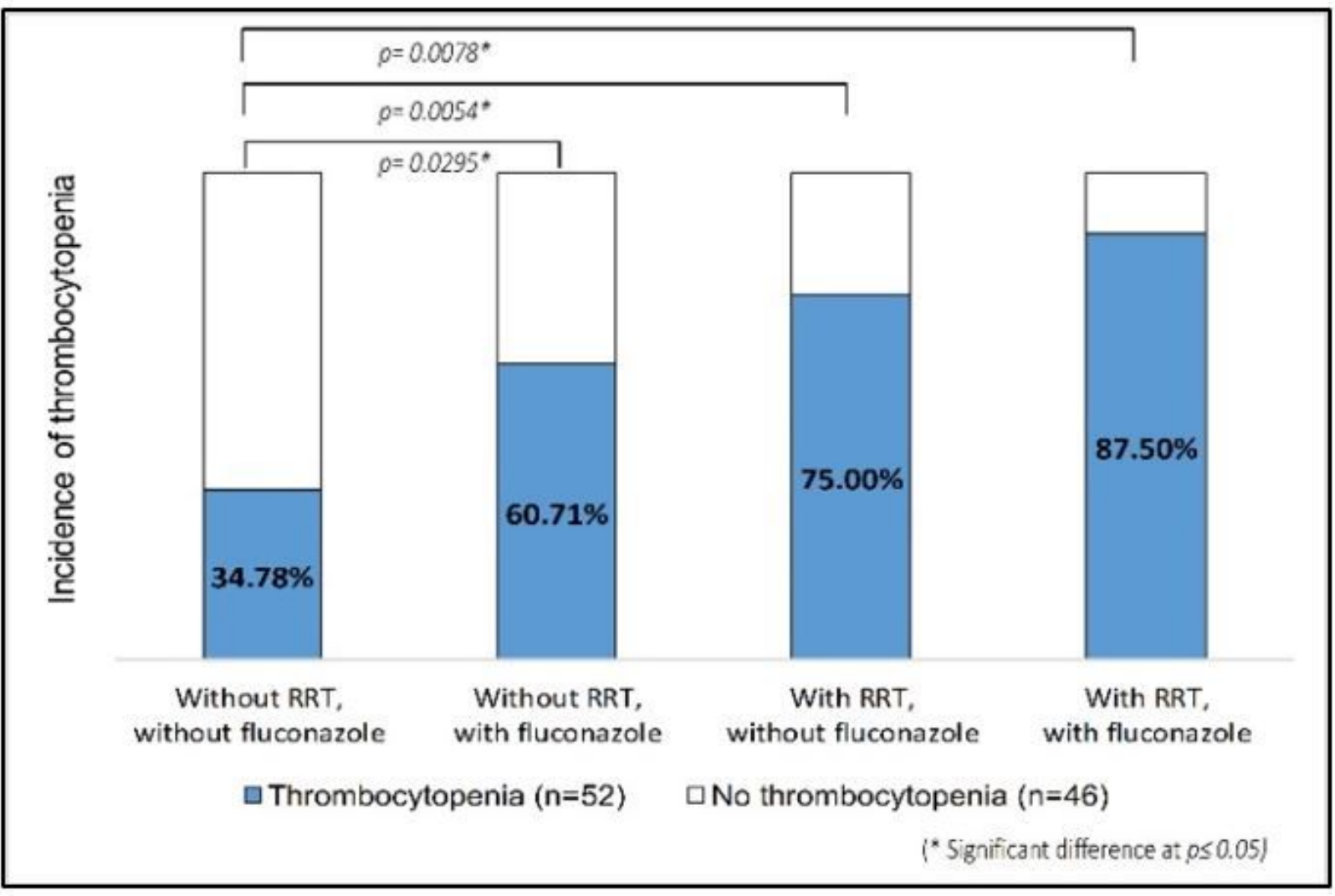

Figure 3

Incidence of linezolid-associated thrombocytopenia among patients who received both RRT and fluconazole, RRT alone, fluconazole alone, and denied RRT and fluconazole

\section{Supplementary Files}

This is a list of supplementary files associated with this preprint. Click to download.

- Supplementaryinformation.docx 